Editorial

\title{
Special Issue on Sciences in Heat Pump and Refrigeration
}

\author{
Takahiko Miyazaki ${ }^{1,2}$ (1) \\ 1 Faculty of Engineering Sciences, Kyushu University, 6-1 Kasuga-koen, Kasuga-shi, Fukuoka 816-8580, Japan; \\ tmiyazak@kyudai.jp \\ 2 International Institute for Carbon-Neutral Energy Research, Kyushu University, 744 Motooka, Nishi-ku, \\ Fukuoka 819-0395, Japan
}

Received: 30 May 2019; Accepted: 4 June 2019; Published: 11 June 2019

\section{Introduction}

The history of heat pump and refrigeration is very long, and ever since mankind acquired mechanical refrigeration more than a century ago, heat pump and refrigeration technologies have made remarkable progress. However, the negative impacts of heat pumps and refrigeration on the global environment became visible over the last several decades. One of the major issues was ozone layer depletion by chlorofluorocarbons (CFCs) and hydrochlorofluorocarbons (HCFCs) that are used as refrigerants of heat pump and refrigeration systems. These materials were, or are going to be, phased out based on an international agreement, the Montreal Protocol. Another major issue is global warming; heat pump and refrigeration systems directly and indirectly release a large amount of greenhouse gases (GHGs). Although the current refrigerants, hydrofluorocarbons (HFCs), have no ozone depletion potential (ODP), they are strong GHGs. For example, the global warming potentials (GWPs) of refrigerants for split-type and packaged air conditioners, such as R410A and R407C, are around 2000 [1]. Some studies have already reported that the impact of HFCs on global warming is not negligible [2,3], and recently, toward the phasing out of HFCs, the regulations in the production and use of them were accelerated by the Kigali Amendment to the Montreal Protocol. Indirect emissions of carbon dioxide by heat pump and refrigeration systems are also significant. The system itself is highly efficient, especially compared with conventional heating systems, but the application of heat pumps and refrigeration is wide. Unfortunately, most of the systems are driven by electricity; therefore, the amount of electricity consumed by heat pumps and refrigeration is huge and still increasing worldwide.

In this context, a vast amount of research related to heat pumps and refrigeration is ongoing. Presently, intensive effort is being made on new artificial refrigerants with low GWP, such as the so-called hydrofluoroolefins (HFOs) [4]. As the design of heat pump and refrigeration systems should be optimized against refrigerants, the simple replacement of refrigerants will, in many cases, cause performance degradation. Therefore, it is essential to know thermophysical properties and heat transfer characteristics for the optimum design of systems. Natural refrigerants, such as water, ammonia, carbon dioxide, hydrocarbons, and air are ideal, and many systems using natural refrigerants are already commercial. Nevertheless, there are still many difficulties in replacing refrigerants for split or packaged air conditioners-which are one of the largest energy consumers in the building sector-with natural refrigerants, due to limitations in safety, size, and cost.

Papers which contributed to this special issue include a variety of scientific and engineering approaches for improvement in system efficiency, as well as for the development of new systems driven by minimal electricity consumption. The studies were expediently categorized into three groups, given in the following. 


\section{Fundamental Process, Components, and Mechanical Vapor Compression}

Several thermodynamic processes, such as heat transfer, phase change, compression, and expansion are the basis of heat pump and refrigeration. Heat transfer is one of key factors which make the system compact. Bashar et al. [5] reported improvement in correlations for predictions of condensation heat transfer and of pressure drop inside a small-diameter heat transfer tube. Inoue et al. [6] also showed measurement results of several HFCs and HFOs in condensation heat transfer and pressure drop. These fundamental data are essential to the optimum design of compact heat exchangers. Improvement of a heat transfer tube using delta-winglet was proposed by Yaningsih et al. [7]. Liang et al. [8] and Hu et al. [9] presented the optimum design and a prediction model of heat exchangers. Other studies [10-13] reported various approaches for improving efficiency and to mitigate GHG emissions. All these studies are indispensable for continuous progress, and guarantee steady steps toward reducing direct and indirect emissions of GHGs.

\section{Next Generation Heat Pump/Refrigeration}

Absorption and adsorption heat pump/refrigeration systems have been proposed as environmentally friendly alternatives to mechanical vapor compression heat pump and refrigeration systems. The main advantages of these systems are how: (i) natural refrigerants, usually water, is used, and (ii) the driving force is low-grade thermal energy, such as solar thermal energy and industrial waste heat. Solar cooling with a combination with absorption refrigeration was investigated by Galindo Luna et al. [14] and Li et al. [15]. In addition, Wang et al. [16] studied the dynamic behavior of an absorption chiller under various operating conditions. In the field of the adsorption heat pump, Maeda et al. [17] provided a critical review on an adsorption heat pump for automobile applications. Grekova et al. [18] studied the applicability of a novel system-adsorption heat transformation - under various climates. Zwarycz-Makles and Majorkowska-Mech [19] contributed with an improvement of a simulation model on an adsorption heat pump. Besides absorption and adsorption, Farikhah [20] reported a numerical study on a thermoacoustic engine and cooler, which is another piece of technology that is able to utilize untapped energy. This research area has been kept active and is gaining importance for next generation heat pump and refrigeration systems.

\section{Related Studies and Future Aspects}

As heat pump and refrigeration studies aim to overcome global environmental issues, a comprehensive viewpoint is also important. Therefore, this special issue has collected a wide range papers, including from surrounding research areas of heat pump and refrigeration, especially related to renewable energy technologies. These studies include solar energy, including a photovoltaics hybrid system [21], solar water heaters [22], ground heat exchangers [23], ground heating [24], cryogenic heat exchangers [25], water extraction from air [26], and sea-water ice-making [27].

Heat pumps and refrigeration can significantly affect the quality of our lives; therefore, the demand of heat pumps and refrigeration will keep increasing, unless the total number of human beings decreases drastically. It is, however, possible to reduce energy consumption and GHG emission for heat pump and refrigeration by using a comprehensive approach. We have to keep a broad vision in this area, spanning from fundamental science to their application.

Funding: This research received no external funding.

Acknowledgments: The editor thank to all the authors and reviewers as well as the editorial and managing team of Applied Sciences for their significant contributions to the special issue. The special issue would not be completed without dedicated effort by all members. In addition, congratulations to all the staff of MDPI on the success of the journal.

Conflicts of Interest: The author declares no conflict of interest. 


\section{References}

1. Mohanraj, M.; Jayaraj, S.; Muraleedharan, C. Environment friendly alternatives to halogenated refrigerants-A review. Int. J. Greenh. Gas Control 2009, 3, 108-119. doi:10.1016/j.ijggc.2008.07.003. [CrossRef]

2. Johnson, E.P. Air-source heat pump carbon footprints: HFC impacts and comparison to other heat sources. Energy Policy 2011, 39, 1369-1381. doi:10.1016/j.enpol.2010.12.009. [CrossRef]

3. Zhao, L.; Zeng, W.; Yuan, Z. Reduction of potential greenhouse gas emissions of room air-conditioner refrigerants: A life cycle carbon footprint analysis. J. Clean. Prod. 2015, 100, 262-268. doi:10.1016/j.jclepro.2015.03.063. [CrossRef]

4. Brown, J.S. HFOs New, Low Global Warming Potential Refrigerants. ASHRAE J. 2009, 51, $22-29$.

5. Bashar, M.K.; Nakamura, K.; Kariya, K.; Miyara, A. Experimental Study of Condensation Heat Transfer and Pressure Drop inside a Small Diameter Microfin and Smooth Tube at Low Mass Flux Condition. Appl. Sci. 2018, 8, 2146. doi:10.3390/app8112146. [CrossRef]

6. Inoue, N.; Hirose, M.; Jige, D.; Ichinose, J. Correlation for Condensation Heat Transfer in a 4.0 mm Smooth Tube and Relationship with R1234ze(E), R404A, and R290. Appl. Sci. 2018, 8, 2267. doi:10.3390/app8112267. [CrossRef]

7. Yaningsih, I.; Wijayanta, A.; Miyazaki, T.; Koyama, S. Impact of blockage ratio on thermal performance of delta-winglet vortex generators. Appl. Sci. 2018, 8, 181. doi:10.3390/app8020181. [CrossRef]

8. Liang, C.; Tong, X.; Lei, T.; Li, Z.; Wu, G. Optimal Design of an Air-to-Air Heat Exchanger with Cross-Corrugated Triangular Ducts by Using a Particle Swarm Optimization Algorithm. Appl. Sci. 2017, 7, 554. doi:10.3390/app7060554. [CrossRef]

9. Hu, W.; Jia, P.; Nie, J.; Gao, Y.; Zhang, Q. A Fast Prediction Model for Heat Transfer of Hot-Wall Heat Exchanger Based on Analytical Solution. Appl. Sci. 2018, 9, 72. doi:10.3390/app9010072. [CrossRef]

10. Seong, K.; Lee, D.; Lee, J. The Effects of Wet Compression by the Electronic Expansion Valve Opening on the Performance of a Heat Pump System. Appl. Sci. 2017, 7, 248. doi:10.3390/app7030248. [CrossRef]

11. Llopis, R.; Sanchez, D.; Cabello, R.; Catalan-Gil, J.; Nebot-Andres, L. Conversion of a Direct to an Indirect Refrigeration System at Medium Temperature Using R-134a and R-507A: An Energy Impact Analysis. Appl. Sci. 2018, 8, 247. doi:10.3390/app8020247. [CrossRef]

12. Chang, S.; Chen, J.; Shi, L. Using Thermal Shock to Inhibit Biofilm Formation in the Treated Sewage Source Heat Pump Systems. Appl. Sci. 2017, 7, 343. doi:10.3390/app7040343. [CrossRef]

13. Yokoyama, R.; Ohkura, M.; Nakamata, T.; Wakui, T. Numerical Analysis for Performance Evaluation of a Multi-Functional CO2 Heat Pump Water Heating System. Appl. Sci. 2018, 8, 1829. doi:10.3390/app8101829. [CrossRef]

14. Galindo Luna, Y.; Gómez Franco, W.; Dehesa Carrasco, U.; Romero Domínguez, R.; Jiménez García, J. Integration of the Experimental Results of a Parabolic Trough Collector (PTC) Solar Plant to an Absorption Air-Conditioning System. Appl. Sci. 2018, 8, 2163. doi:10.3390/app8112163. [CrossRef]

15. Li, Z.; Yu, J.; Chen, E.; Jing, Y. Off-Design Modeling and Simulation of Solar Absorption-Subcooled Compression Hybrid Cooling System. Appl. Sci. 2018, 8, 2612. doi:10.3390/app8122612. [CrossRef]

16. Wang, J.; Shang, S.; Li, X.; Wang, B.; Wu, W.; Shi, W. Dynamic Performance Analysis for an Absorption Chiller under Different Working Conditions. Appl. Sci. 2017, 7, 797. doi:10.3390/app7080797. [CrossRef]

17. Maeda, S.; Thu, K.; Maruyama, T.; Miyazaki, T. Critical Review on the Developments and Future Aspects of Adsorption Heat Pumps for Automobile Air Conditioning. Appl. Sci. 2018, 8, 2061. doi:10.3390/app8112061. [CrossRef]

18. Grekova, A.; Gordeeva, L.; Sapienza, A.; Aristov, Y. Adsorption Transformation of Heat: The Applicability in Various Climatic Zones of the Russian Federation. Appl. Sci. 2019, 9, 139. doi:10.3390/app9010139. [CrossRef]

19. Zwarycz-Makles, K.; Majorkowska-Mech, D. Gear and Runge-Kutta Numerical Discretization Methods in Differential Equations of Adsorption in Adsorption Heat Pump. Appl. Sci. 2018, 8, 2437. doi:10.3390/app8122437. [CrossRef]

20. Farikhah, I.; Ueda, Y. Numerical Calculation of the Performance of a Thermoacoustic System with Engine and Cooler Stacks in a Looped Tube. Appl. Sci. 2017, 7, 672. doi:10.3390/app7070672. [CrossRef]

21. Dai, N.; Xu, X.; Li, S.; Zhang, Z. Simulation of Hybrid Photovoltaic Solar Assisted Loop Heat Pipe/Heat Pump System. Appl. Sci. 2017, 7, 197. doi:10.3390/app7020197. [CrossRef] 
22. Hasan, M.; Mahadi, M.; Miyazaki, T.; Koyama, S.; Thu, K. Exergy Analysis of Serpentine Thermosyphon Solar Water Heater. Appl. Sci. 2018, 8, 391. doi:10.3390/app8030391. [CrossRef]

23. Lee, S.; Park, S.; Kang, M.; Choi, H. Field Experiments to Evaluate Thermal Performance of Energy Slabs with Different Installation Conditions. Appl. Sci. 2018, 8, 2214. doi:10.3390/app8112214. [CrossRef]

24. Park, M. A Study on the Improvement Effect and Field Applicability of the Deep Soft Ground by Ground Heating Method. Appl. Sci. 2018, 8, 852. doi:10.3390/app8060852. [CrossRef]

25. Yang, S.; Liu, Z.; Fu, B.; Chen, Y. Influence of Frost Growth and Migration in Cryogenic Heat Exchanger on Air Refrigerator. Appl. Sci. 2019, 9, 753. doi:10.3390/app9040753. [CrossRef]

26. Cattani, L.; Magrini, A.; Cattani, P. Water Extraction from Air by Refrigeration-Experimental Results from an Integrated System Application. Appl. Sci. 2018, 8, 2262. doi:10.3390/app8112262. [CrossRef]

27. Lee, H.K.; Choi, K.H.; Yoon, J.I.; Moon, C.G.; Jeon, M.J.; Lee, J.H.; Lee, K.S.; Son, C.H. Performance Characteristics of a Seawater Ice-Making Device Using a Scraped Surface Double Tube Evaporator. Appl. Sci. 2018, 8, 2063. doi:10.3390/app8112063. [CrossRef]

(C) 2019 by the author. Licensee MDPI, Basel, Switzerland. This article is an open access article distributed under the terms and conditions of the Creative Commons Attribution (CC BY) license (http:// creativecommons.org/licenses/by/4.0/). 